\title{
BMJ Open Injuries and frequent use of emergency department services: a systematic review
}

\author{
Catherine Laferté, ${ }^{1}$ Andréa Dépelteau (D) , ${ }^{2}$ Catherine Hudon (D) ${ }^{1,2,3}$
}

To cite: Laferté C, Dépelteau A, Hudon C. Injuries and frequent use of emergency department services: a systematic review. BMJ Open 2020;10:e040272. doi:10.1136/ bmjopen-2020-040272

- Prepublication history and additional material for this paper are available online. To view these files, please visit the journal online (http://dx.doi. org/10.1136/bmjopen-2020040272).

Received 11 May 2020 Revised 20 November 2020 Accepted 01 December 2020

Check for updates

(C) Author(s) (or their employer(s)) 2021. Re-use permitted under CC BY-NC. No commercial re-use. See rights and permissions. Published by BMJ.

${ }^{1}$ Faculté de Médecine et des Sciences de la Santé, Université de Sherbrooke, Sherbrooke, Quebec, Canada

2École de Réadaptation, Université de Sherbrooke, Sherbrooke, Quebec, Canada ${ }^{3}$ Département de Médecine de Famille et de Médecine d'Urgence, Université de Sherbrooke, Sherbrooke, Quebec, Canada

\section{Correspondence to} Professor Catherine Hudon; catherine.hudon@usherbrooke. ca

\section{ABSTRACT}

Objective To review all studies having examined the association between patients with physical injuries and frequent emergency department (ED) attendance or return visits.

Design Systematic review.

Data source Medline, Cumulative Index to Nursing and Allied Health Literature (CINAHL) and PsycINFO databases were searched up to and including July 2019.

Eligibility criteria English and French language publications reporting on frequent use of ED services (frequent attendance and return visits), evaluating injured patients and using regression analysis.

Data extraction and synthesis Two independent reviewers screened the search results, and assessed methodological quality using the Joanna Briggs Institute tool for prevalence studies. Results were collated and summarised using a narrative synthesis. A sensitivity analysis was performed to evaluate the repercussions of removing a study that did not meet the quality criteria. Results Of the 2184 studies yielded by this search, 1957 remained after the removal of duplicates. Seventyeight studies underwent full-text screening leaving nine that met the eligibility criteria and were included in this study: five retrospective cohort studies; two prospective cohort studies; one cross-sectional study; and one casecontrol study. Different types of injuries were represented, including fractures, trauma and physical injuries related to falls, domestic violence or accidents. Sample sizes ranged from 200 to 1259 809. Six studies included a geriatric population while three addressed a younger population. Of the four studies evaluating the relationship between injuries and frequent ED use, three reported an association. Additionally, of the five studies in which the dependent variable was return ED visits, three articles identified a positive association with injuries.

Conclusions Physical injuries appear to be associated with frequent use of ED services (frequent ED attendance as well as return ED visits). Further research into factors including relevant youth-related covariates such as substance abuse and different types of traumas should be undertaken to bridge the gap in understanding this association.

\section{INTRODUCTION}

Overcrowding in emergency departments (EDs) is a growing concern impeding the provision of care $^{12}$ that has reportedly reached crisis proportions within many countries. ${ }^{34}$ This increasing utilisation of EDs, associated with a plethora of deleterious patient
Strengths and limitations of this study

- A systematic search strategy, developed in collaboration with an information specialist, was undertaken across three databases.

- Independent evaluators assessed the screening process, conducted the quality evaluation as well as the synthesis.

- There is a wide range of physical injuries evaluated by the studies included in this review.

- The heterogeneity of the definitions of frequent emergency department use makes it difficult to compare the population in the studies assessed.

outcomes, has garnered attention from policy-makers, enabling them to evaluate patient populations who are disproportionately contributing to these recurrent admissions. Indeed, frequent $\mathrm{ED}$ use, including both frequent attendance and return visits, contributes to this unreasonable burden on the healthcare system by consuming a substantial amount of medical care resources.

Even though many studies have sought to characterise the factors related to this excessive mobilisation of healthcare services, there is no universal consensus regarding the threshold to define frequent use of EDs. Definitions for frequent attendance range from 2 visits to 20 visits per year, but commonly, authors set the threshold at four visits or more within a calendar year. ${ }^{56}$ Time frame for a return visit ranges from 28 days to 6 months. ${ }^{7}$ Prior studies have identified frequent attendance and return visit as a proxy indicator of continuous decline of healthcare service particularly when they occur proximate to the index ED visit. ${ }^{8}$ Both frequent attenders and return visitors were therefore considered in order to draw up an overall portrait of frequent ED utilisation.

Studies across the globe state that this increase in ED utilisation is an international phenomenon $^{9}$ which has not left Canada unscathed. Between 2017 and 2018, 11266 $609 \mathrm{ED}$ visits were reported in Canada and frequent ED users account for 30.6\% (3 442 
223 visits). Among these consults, 2096583 were injuryrelated ED visits. ${ }^{10}$ Trauma rates have reached epidemic proportions which have a significant economic impact. ${ }^{11}$ In this article, the term 'injury' is defined as damage 'caused by acute exposure to physical agents such as mechanical energy, heat, electricity, chemicals, and ionising radiation interacting with the body in amounts or at rates that exceed the threshold of human tolerance'. ${ }^{12}$ Injury-related diagnoses are prevalent in adulthood, but only a few studies have explored their association with the frequent use of EDs.

Sufficient understanding of the underlying motives of this heterogeneous patient group is important to fill the dearth in our current knowledge of ED utilisation and to implement appropriate and sustainable interventions to improve patient flow and care through hospitals. Thus, this systematic review aims to review all studies having examined the association between injuries and frequent ED use.

\section{METHODS}

\section{Review design}

This systematic review was conducted according to the principles stated in the Joanna Briggs Institute (JBI) Reviewers' Manual 2014. ${ }^{1314}$ This article was designed in accordance with the Preferred Reporting Items for Systematic Reviews and Meta-Analyses Checklist. ${ }^{15}$ Systematic reviews present exhaustive, critical assessments of the published literature on a given topic in order to provide evidence on a broad problem to guide clinical practice.

\section{Data sources and search strategy}

A search strategy was undertaken in Medline, PsycINFO and CINAHL databases to extract studies dated up to and including July 2019. The search included medical subject heading terms and clustered keywords pertaining to a physically injured population, and to frequent users of ED services. The reference lists of relevant reviews and articles were hand searched to identify other studies of interest. A Master of Information Science helped design the search strategy, shown in online supplemental file 1.

\section{Eligibility criteria}

English- and French-language articles were included if they:

1. Documented frequent use of ED services (frequent attendance and return visits).

2. Evaluated physically injured patients.

3. Used an observational study design, which included prospective and retrospective cohort studies, casecontrol studies and cross-sectional studies using a regression analysis.

Articles reporting injuries arising directly from alcohol or drug intoxication were excluded since the association of this factor with frequent ED use has been long established and recognised by previous studies. ${ }^{16}$ In addition, self-harm injuries, defined as a deliberate direct harming regardless of suicidal intent, were also excluded. Finally, studies addressing only a paediatric population or including only injured participants were excluded from this review, since injury could not be used as an independent variable.

\section{Study selection, data extraction and synthesis}

All screened literature was imported into Zotero to make organisation easier and to remove duplicates. The lead author (CL) conducted the first screening of article titles and abstracts independently to exclude studies that were clearly not eligible. A second reviewer $(\mathrm{AD}$ or $\mathrm{CH})$ then performed a full-text assessment of the uncertain articles retrieved following the initial screening. A hand search was conducted by CL by examining reference lists to identify additional relevant studies. Subsequently, two reviewers (CL and $\mathrm{CH}$ ) separately carried out a screening of full texts in light of eligibility criteria. Authors of the studies were contacted to complete any missing information. Finally, the lead author (CL) designed and completed a chart, validated by $\mathrm{CH}$, which presents the search's findings: authors, year of publication, country, study aim, sample characteristics, definition of injury and frequent ED use, results, and covariates. This chart was used to amalgamate, summarise and report the results discussed in the narrative synthesis.

\section{Quality assessment}

To assess overall methodological quality, two reviewers ( $\mathrm{CL}$ and $\mathrm{AD}$ ) independently used the quality assessment checklist found in the Joanna Briggs Institute (JBI) Manual for Prevalence and Incidence Studies Handbook ${ }^{13}$ presented in online supplemental file 2. This tool includes a set of nine standard questions covering topics such as sample frame and size, coverage and appropriateness of the analysis. In case of discrepancy, a third party $(\mathrm{CH})$ joined the discussion in order to reach a consensus. A sensitivity analysis was conducted in order to assess the extent to which removing the studies that failed to meet more than five of the nine quality criteria would impact the conclusions of this review. An 'unclear' mention regarding a question indicates that according to the authors, the study in question does not fulfil this criterion.

\section{Patient and public involvement}

Patients and/or the public were not involved in the design, or conduct, or reporting or dissemination plans of this research.

\section{RESULTS}

\section{Literature search}

Of the 2184 studies yielded by this search, 1957 remained after the removal of duplicates. Seventy-eight underwent full-text screening and nine were included in this study. The flow chart (figure 1) presents the search and selection process, as well as the reasons behind the exclusion of the 69 studies that were rejected following the full-text 


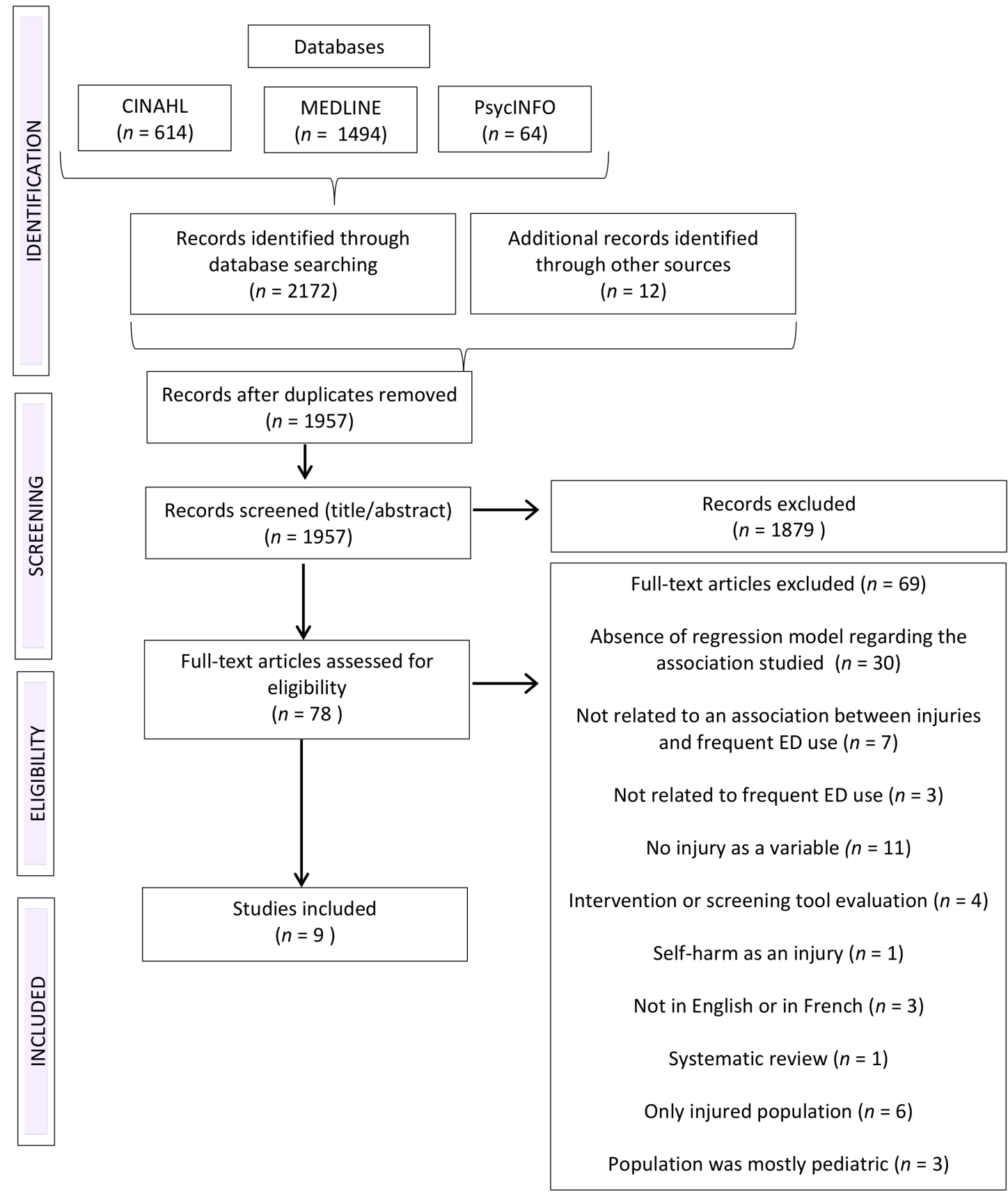

Figure 1 Flow chart summarising the literature search and study selection.

screening. The articles in the final data set include two prospective cohort studies, ${ }^{17}{ }^{18}$ five retrospective cohort studies, ${ }^{19-23}$ one cross-sectional study ${ }^{24}$ and one prospective case-control study. ${ }^{23}$ All nine studies selected were published between 1994 and 2019. Four were conducted in the USA, ${ }^{18} 192223$ two were conducted in Canada,, 24 one in Italy, ${ }^{20}$ one in Israel $^{25}$ and one was conducted in seven countries. ${ }^{17}$

\section{Description of studies}

Population, sample size and data sources

Sample totals varied from 200 to 1259809 participants. Six studies recruited only an older population above 65 or 75 years old, ${ }^{17-1921-23}$ whereas three studies ${ }^{20} 24$ included younger individuals from the age of 14 or 16 years old. Data sources for the measures of associated variables also differed: five used administrative databases or medical records, ${ }^{19222325}$ two used questionnaires ${ }^{1724}$ and two used a combination of both methods. ${ }^{1821}$

\section{Definition of frequent ED use}

The outcome variables had to target a measure of frequent ED use, either frequent attendance or return ED visits. Definitions of frequent attenders over a 1-year period differed between the four studies evaluating this variable. The threshold for frequent attendance varied from two to six ED visits. Additionally, the five studies exploring the association between injuries and return visits involved 
heterogeneous study periods for this dependent variable. ED returns were evaluated within the month following the initial visit or during a 6-month to 18 -month period. One examined patients had at least two significant trauma visits. $^{25}$

\section{Definition of injury}

Studies cover a spectrum of clinical disorders related to a physical injury. One study included all E-code diagnoses as injuries, four studies evaluated traumatic or accidental injuries, ${ }^{1723-25}$ four studies specifically analysed falls, ${ }^{1721-23}$ three inquired about fractures ${ }^{1822}$ and one assessed domestic violence. ${ }^{20}$

\section{Associated variables}

Multinomial logistic regression models were used in seven studies, one study used longitudinal Poisson regression models ${ }^{18}$ and one study used univariate logistic regression. ${ }^{17}$ Table 1 presents the covariates used to adjust regression models.

\section{Synthesis of outcomes}

Six of the nine studies concluded to an association between patients with physical injuries and frequent ED use. Three of four studies reported an association between patients suffering from traumatic injuries and frequent attendance. Of these three, a study by Castillo $e t$ $a l^{19}$ indicates that any injury identified with an E-code is more likely to occur among frequent attenders then less frequent users (OR 3.82; 95\% CI 3.75 to 3.89). Furthermore, Brown and Goel $^{24}$ assessed that significant accidents are strongly correlated with two or more ED visits (OR, 3.06; 95\% CI 2.33 to 4.04) compared with those who visited an ED only one time. Lastly, Leporatti $e t a l^{20}$ reported that in comparison with normal users, frequent and highly frequent ED attenders are more often defined by injury resulting specifically from domestic violence $(\mathrm{RRR}=2.245 ; \mathrm{p}<0.001$ and $\mathrm{RRR}=3.686 ; \mathrm{p}<0.001$ respectively). On the other hand, McCusker $e t a l^{21}$ drew the conclusion that patients reporting two falls or more in the past 6 months were not significantly associated with three or more return ED visits in 6 months (OR 0.99; $95 \%$ CI 0.50 to 2.00$)$.

Furthermore, studies have explored the relationship between injured patients and return ED visits. Of the five articles, three concluded to an association with repeat attendance after a history of injury. LaMantia et alstate that patients discharged following an accident often returned to the ED within 30 days. Moreover, a study conducted by Zimmerman $e t a l^{18}$ assesses that experiencing a fracture was a predictor of higher use of ED during the month (RR $18.78 ; 95 \%$ CI 14.28 to $24.69 ; \mathrm{p}<0.001$ ) and the 6 -month to 12 -month period post-fracture (RR 1.90; $95 \%$ CI 1.12 to $3.21 ; \mathrm{p}<0.05)$. In addition, patients with a first hip fracture particularly showed higher use of ED during the month following the fracture (RR 6.61; 95\% CI 3.33 to 13.41; $\mathrm{p}<0.001)$. Finally, Sayfan and Berlin ${ }^{25}$ concluded that a history of previous significant traumatic events was a strong predictor for recurrent trauma (AOR 10.36; 95\% CI 3.10 to 34.58 ). In contrast, the analysis of Sri-on et $a l^{22}$ pointed out that patients with at least one fall in the previous 3 months or with a history of hip fracture were not statistically associated with an ED revisit within 6 months (OR 1.37; 95\% CI 0.83 to 2.24 and OR 1.29; $95 \%$ CI 0.56 to 3.00 , respectively). Similarly, Costa et $\mathrm{al}^{17}$ assessed that neither falls occurring in the past 90 days nor traumatic injuries were significantly associated with repeat ED or hospital use within 28 days post-index ED visit among outpatients (OR 1.04; 95\% CI 0.72 to 1.50 and OR $0.94 ; 95 \%$ CI 0.48 to 1.82 , respectively).

\section{Quality assessment}

Of the nine studies, eight reached the quality threshold established beforehand. The sensitivity analysis indicated that removal of the lowest quality study ${ }^{25}$ did not alter our results. However, instead of a majority of six articles out of nine assessing a positive association, five out of eight reached this conclusion.

\section{DISCUSSION}

Of the nine studies assessed, six concluded to an association between injuries and frequent use of ED services. Among the four articles studying frequent attendance, a majority of three articles found an association between injuries and frequent use. Additionally, a smaller proportion of three out of five articles evaluating return visits concluded to an association. After removing the lower quality study, five out of eight presented this conclusion: three of the four articles assessing frequent ED use and two of the four evaluating repeat ED visits.

Repeat episodes of injury may represent up to $44 \%$ of trauma consults in urban settings. ${ }^{26}$ Often assumed to be an acute episodic event, urban trauma could also epitomise a chronic recurrent issue related to the victims' lifestyle, environment and other personal factors. ${ }^{26} \mathrm{~A}$ study ${ }^{20}$ distinguished between frequent (3 to 5 visits/year) and highly frequent attenders $(\geq 6$ visits/year). Being a victim of an injury resulting from domestic violence was a stronger predictor of highly frequent $\mathrm{ED}$ use than frequent use in the logistic regression model, after controlling for other factors such as substance abuse and psychological distress. Moreover, a retrospective analysis concluded that domestic violence was at least two times more common among return visitors (defined as patients with two or more unrelated visits) than single-visit patients: $3.5 \%$ compared with $1.6 \% \quad(\mathrm{p}<0.0003) .{ }^{27}$ Indeed, domestic violence is an example representing how traumas, reckoned as acute events, can indeed embody more chronic conditions. Thus, recidivist trauma should be screened for domestic violence in order to prevent further repeat episodes of injury.

In our review, half of the six articles including a geriatric population concluded in a positive correlation 


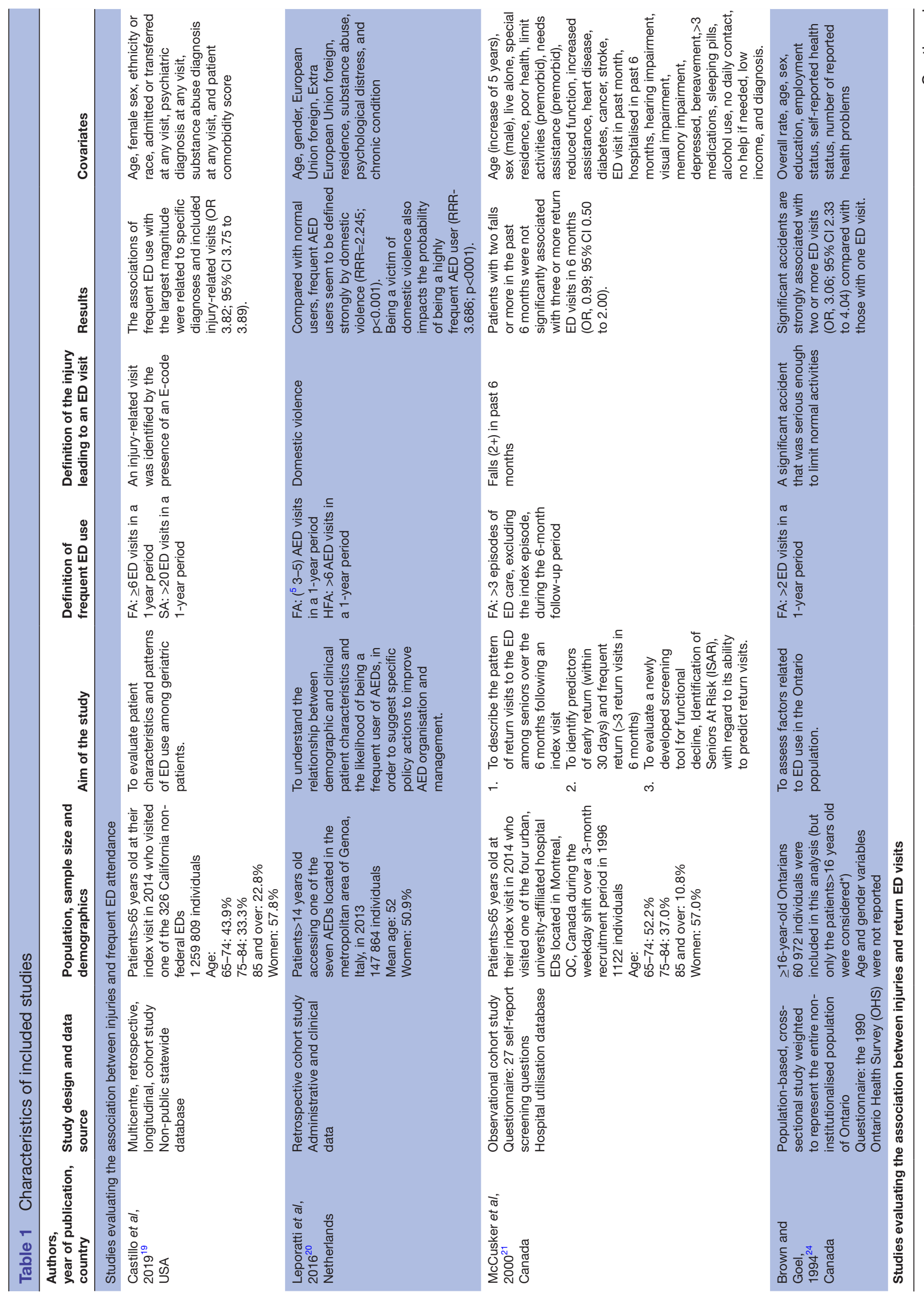

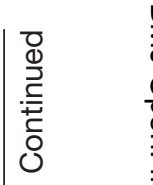




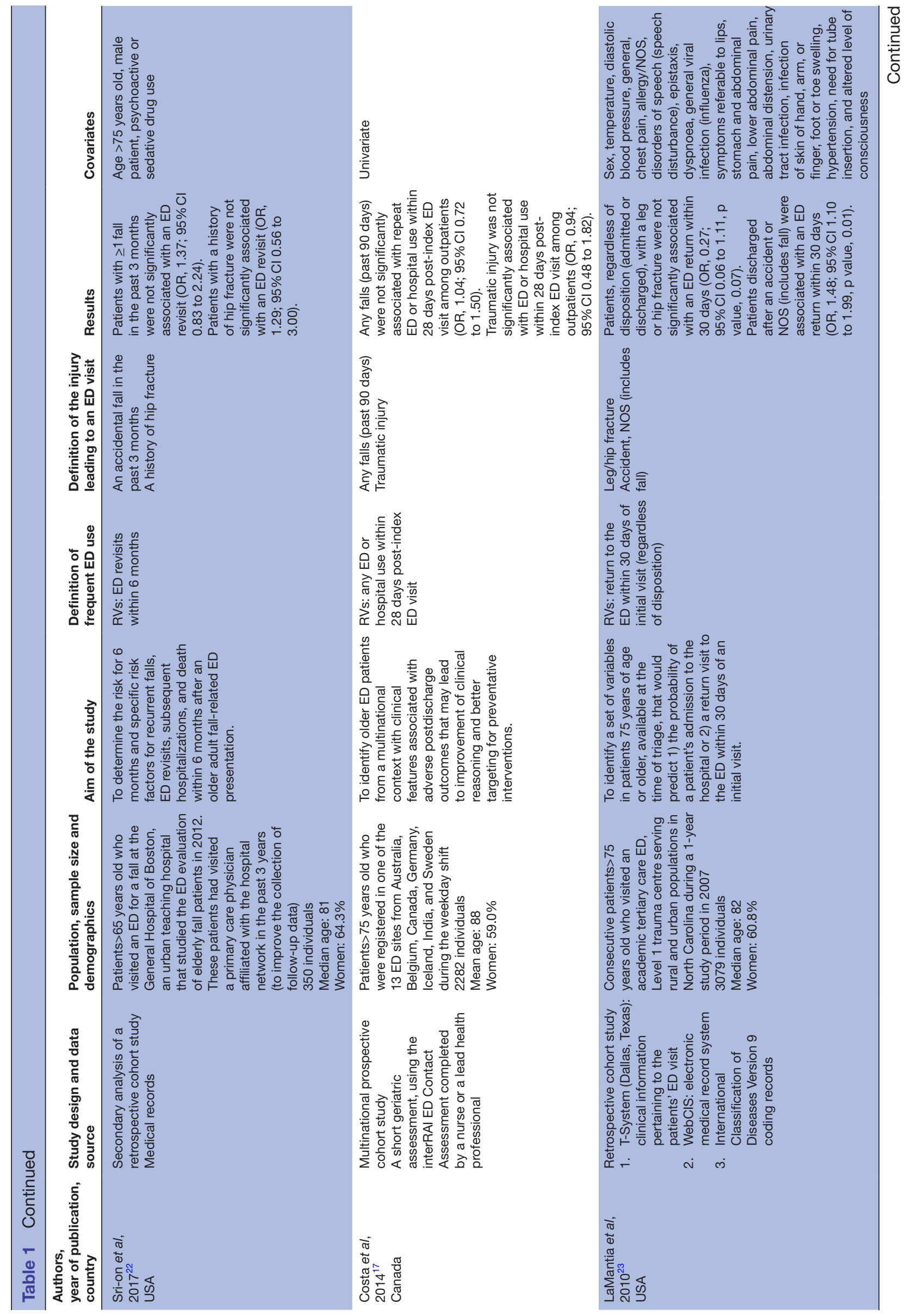




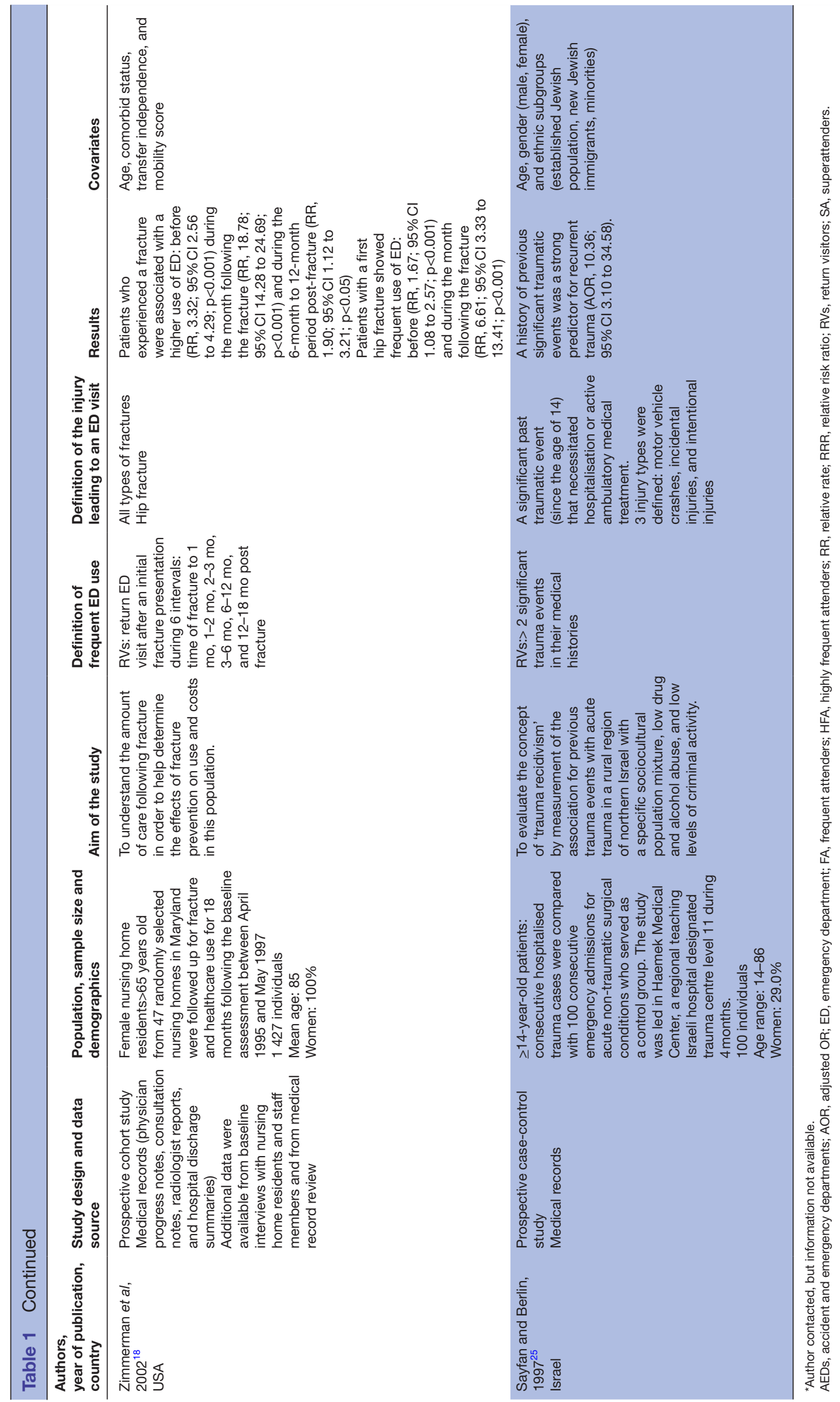


between injuries and frequent ED use. On the other hand, the three articles including younger participants concluded in a positive association between injuries and frequent ED use, even after correcting for 'age' in the models. However, only one study ${ }^{20}$ out of the three controlled for substance abuse in their model. Further studies should be undertaken among a younger population to confirm this association between injuries and frequent $\mathrm{ED}$ use, controlling for relevant variables such as alcohol or drug intoxication.

\section{Strengths and limitations}

The greatest strengths of this systematic review are the systematic and rigorous literature search strategy implemented to identify relevant studies and the fact that a minimum of two evaluators assessed the screening process, as well as conducting the quality evaluation and the synthesis.

The limitations of this review include certain methodological limitations and considerable variation among the studies included. One of the main limitations of the selected articles concerns the heterogeneity of the definitions of frequent ED use, which presents an impediment to comparison of the injured patients participating in the studies assessed. Another limitation relates to the wide range of physical injuries evaluated by the nine articles included. This small number of selected articles hinders an analysis depending on the type of injury (accidents, falls, domestic violence, fractures, etc) and highlights that little research has been conducted to explore injuries and frequent ED use. While we have searched for studies that adjusted for covariates that might have influenced the association between injury and frequent ED use, each study considers different covariates and some studies do not appear to have included known predictors of repeat attendance.

\section{CONCLUSIONS}

This systematic review suggests that physical injuries are associated with frequent use of EDs. Further research should be undertaken to bridge the gap in understanding this association among young adults and to provide a more comprehensive picture by including key variables in subsequent studies, such as age, alcohol or drug intoxication, and type of injury.

Correction notice This article has been corrected since it first published. The provenance and peer review statement has been included.

Acknowledgements The authors would like to acknowledge Mireille LégerRousseau, Master of Information Science, for her invaluable guidance in developing rigorous search strategies, Bonita van Doorn for the editorial review and Mireille Lambert for assistance in the revision of the manuscript. In addition, the authors wish to thank the Faculté de Médecine et des Sciences de la Santé de l'Université de Sherbrooke for the grant awarded to lead author Catherine Laferté, a secondyear medical student.

Contributors All authors made substantial contributions to the conception and design of the work. $\mathrm{CL}$ undertook the analysis of the data with the regular input of $\mathrm{AD}$ and $\mathrm{CH}$. CL wrote the first drafts of the manuscript under the supervision of $\mathrm{CH}$, and with successive comments of AD. All authors approved the submitted version.
Funding This project received a grant from the Faculté de Médecine et des Sciences de la Santé de l'Université de Sherbrooke.

Competing interests None declared.

Patient consent for publication Not required.

Provenance and peer review Not commissioned; externally peer reviewed.

Data availability statement All data relevant to the study are included in the article or uploaded as supplementary information. Further details on studies included in this review can be retrieved by contacting the corresponding author.

Supplemental material This content has been supplied by the author(s). It has not been vetted by BMJ Publishing Group Limited (BMJ) and may not have been peer-reviewed. Any opinions or recommendations discussed are solely those of the author(s) and are not endorsed by BMJ. BMJ disclaims all liability and responsibility arising from any reliance placed on the content. Where the content includes any translated material, BMJ does not warrant the accuracy and reliability of the translations (including but not limited to local regulations, clinical guidelines, terminology, drug names and drug dosages), and is not responsible for any error and/or omissions arising from translation and adaptation or otherwise.

Open access This is an open access article distributed in accordance with the Creative Commons Attribution Non Commercial (CC BY-NC 4.0) license, which permits others to distribute, remix, adapt, build upon this work non-commercially, and license their derivative works on different terms, provided the original work is properly cited, appropriate credit is given, any changes made indicated, and the use is non-commercial. See: http://creativecommons.org/licenses/by-nc/4.0/.

\section{ORCID iDs}

Andréa Dépelteau http://orcid.org/0000-0003-1820-5218

Catherine Hudon http://orcid.org/0000-0001-6140-9916

\section{REFERENCES}

1 Forero R, Hillman KM, McCarthy S, et al. Access block and ED overcrowding. Emerg Med Australas 2010;22:119-35.

2 Derlet RW. Overcrowding in emergency departments: increased demand and decreased capacity. Ann Emerg Med 2002;39:430-2.

3 Jayaprakash N, O'Sullivan R, Bey T, et al. Crowding and delivery of healthcare in emergency departments: the European perspective. West J Emerg Med 2009;10:233-9.

4 Ospina MB, Bond K, Schull M, et al. Key indicators of overcrowding in Canadian emergency departments: a Delphi study. CJEM 2007;9:339-46.

5 Pines JM, Asplin BR, Kaji AH, et al. Frequent users of emergency department services: gaps in knowledge and a proposed research agenda. Acad Emerg Med 2011;18:e64-9.

6 Locker TE, Baston S, Mason SM, et al. Defining frequent use of an urban emergency department. Emerg Med J 2007;24:398-401.

7 Naughton C, Drennan J, Treacy P, et al. The role of health and nonhealth-related factors in repeat emergency department visits in an elderly urban population. Emerg Med J 2010;27:683-7.

8 Ladha KS, Young JH, Ng DK, et al. Factors affecting the likelihood of presentation to the emergency department of trauma patients after discharge. Ann Emerg Med 2011;58:431-7.

9 Pines JM, Hilton JA, Weber EJ, et al. International perspectives on emergency department crowding. Acad Emerg Med 2011;18:1358-70.

10 Canadian Institute for Health Information. National ambulatory care reporting system metadata (NACRS) 2017-2018. Ottawa, 2018.

11 Harlan LC, Harlan WR, Parsons PE. The economic impact of injuries: a major source of medical costs. Am J Public Health 1990;80:453-9.

12 Holder Y, Peden M, Krug E. Injury surveillance guidelines. Geneva: Wolrd Health Organization, 2001.

13 Joanna Briggs Institute. Joanna Briggs Institute Reviewers' Manual: 2014 edition / Supplement. South Australia: The Joanna Briggs Institute, 2014.

14 Munn Z, Moola S, Riitano D, et al. The development of a critical appraisal tool for use in systematic reviews addressing questions of prevalence. Int J Health Policy Manag 2014;3:123-8.

15 Moher D, Liberati A, Tetzlaff J, et al. Preferred reporting items for systematic reviews and meta-analyses: the PRISMA statement. Ann Intern Med 2009;151:W64:264-9.

16 Baldassarre M, Caputo F, Pavarin RM, et al. Accesses for alcohol intoxication to the emergency department and the risk of rehospitalization: an observational retrospective study. Addict Behav 2018;77:1-6. 
17 Costa AP, Hirdes JP, Heckman GA, et al. Geriatric syndromes predict postdischarge outcomes among older emergency department patients: findings from the interRAI multinational emergency department study. Acad Emerg Med 2014;21:422-33.

18 Zimmerman S, Chandler JM, Hawkes W, et al. Effect of fracture on the health care use of nursing home residents. Arch Intern Med 2002;162:1502-8.

19 Castillo EM, Brennan JJ, Howard J, et al. Factors associated with geriatric frequent users of emergency departments. Ann Emerg Med 2019;74:270-5.

20 Leporatti L, Ameri M, Trinchero C, et al. Targeting frequent users of emergency departments: prominent risk factors and policy implications. Health Policy 2016;120:462-70.

21 McCusker J, Cardin S, Bellavance F, et al. Return to the emergency department among elders: patterns and predictors. Acad Emerg Med 2000;7:249-59.
22 Sri-On J, Tirrell GP, Bean JF, et al. Revisit, subsequent hospitalization, recurrent fall, and death within 6 months after a fall among elderly emergency department patients. Ann Emerg Med 2017;70:516-21.

23 LaMantia MA, Platts-Mills TF, Biese K, et al. Predicting hospital admission and returns to the emergency department for elderly patients. Acad Emerg Med 2010;17:252-9.

24 Brown EM, Goel V. Factors related to emergency department use: results from the Ontario health survey 1990. Ann Emerg Med 1994;24:1083-91.

25 Sayfan J, Berlin Y. Previous trauma as a risk factor for recurrent trauma in rural Northern Israel. J Trauma 1997;43:123-5.

26 Sims DW, Bivins BA, Obeid FN, et al. Urban trauma: a chronic recurrent disease. J Trauma 1989;29:940-6.

27 Kwan RO, Cureton EL, Dozier KC, et al. Gender differences among recidivist trauma patients. J Surg Res 2011;165:25-9. 